\title{
Mulher e família no Programa Bolsa-Escola: maternidades veiculadas e instituídas pelos anúncios televisivos
}

\author{
Carin Klein ${ }^{* *}$
}

\begin{abstract}
Resumo
Este artigo problematiza alguns processos de produção $e$ veiculação de representações de maternidade, tomando como referência o Programa Nacional Bolsa-Escola, e insere-se no campo da teorização cultural, principalmente na perspectiva dos Estudos Culturais e dos Estudos Feministas, nas vertentes que têm proposto uma aproximação crítica com a análise pós-estruturalista. Para a operacionalização do trabalho, selecionei um conjunto de anúncios televisivos que divulgaram o Programa à população no primeiro ano de sua implantação. Exploro os anúncios com o intuito de analisar os diferentes modos de representar e significar a maternidade. Discuto como se organiza e divulga, no âmbito do Programa, um conjunto de ensinamentos e propostas a serem desenvolvidas, principalmente na família, a fim de buscar (re)colocar, sobretudo, as mulheres-mães e a educação das crianças no centro desses debates.
\end{abstract}

Palavras-chave: Programa Nacional Bolsa-Escola, Maternidade, Relações de Gênero.

\footnotetext{
* Recebido para publicação em março de 2006, aceito em outubro de 2006.

*** Doutoranda em Educação, na linha de pesquisa Educação, Sexualidade e Relações de Gênero da UFRGS. carink@terra.com.br
} 
Mulher e família no Programa Bolsa-Escola

Woman and Family at the Bolsa-Escola Program:

Maternities Propagated and Instituted Through TV Advertisements

\begin{abstract}
This work discusses and questions some processes of production and propagation of maternity representations, having the National Bolsa-Escola Program as its starting point, and localized in the field of cultural theory, mainly from the perspectives of both Cultural Studies and Feminist Studies, with a critical approximation to the post-structuralist analysis. In order to carry out the work, I have selected a series of television advertisements used to publicize the Program in its first year of implementation. I have explored these advertisements in order to analyze the different ways through which maternity has been represented and meant. I have discussed how a set of teachings and proposals was publicized in the Program so as to be mainly developed by the families, thus relocating women/mothers and children's education into the center of those debates.
\end{abstract}

Key Words: Programa Nacional Bolsa-Escola, Maternity, Gender Relations. 
Em horário considerado nobre pelos meios de comunicação, no dia 15 de novembro de 2001, foi veiculada, no espaço político reservado aos partidos, uma mensagem em rede nacional de TV falando que o Brasil do Programa da Social Democracia Brasileira (PSDB) investia numa grande Rede de Proteção Social através de importantes programas educacionais, dentre os quais se inseria o Programa Bolsa-Escola. ${ }^{1}$ O Programa visava a proporcionar uma suplementação mensal de renda às famílias em situação de pobreza - renda per capita igual ou inferior a $\mathrm{R} \$ 90,00$ - para que mantivessem seus/suas filhos/as freqüentando a escola.

Do modo como eram apresentadas, as propostas desenvolvidas pelo Programa posicionavam as mulheres-mães como agentes prioritárias para a sua implementação, sendo "imprescindível" contar com sua ajuda e participação. Primeiro, elas auxiliariam na permanência de suas crianças na rede escolar, com a intenção de se chegar aos $100 \%$ de crianças escolarizadas. Segundo, melhorariam a qualidade do ensino através da efetiva presença da família, que, na grande maioria dos textos, restringiase à mulher-mãe, no processo de aprendizagem dos/as seus/suas filhos/as. Terceiro, com o recebimento do benefício monetário as mulheres aplicariam os recursos adquirindo bens que aliviariam as condições de privação das suas crianças.

Por considerar que os efeitos de tais discursos são representativos na materialidade do cotidiano ${ }^{2}$, principalmente no que diz respeito à produção de identidades de gênero, é que

1 Os Programas Bolsa-Escola, Bolsa-Alimentação, Auxílio-Gás e Cartão Alimentação foram unificados constituindo o atual Programa Bolsa-Família. Os programas Bolsa-Escola, Bolsa-Alimentação e Auxílio-Gás foram instituídos na segunda gestão do Governo Fernando Henrique Cardoso (1999-2002). O Cartão Alimentação foi lançado em 2003.

2 Essas mensagens são divulgadas diariamente nos meios de comunicação através de propagandas e anúncios ou mesmo pelos programas, transmitidos em rede nacional, que envolvem prefeituras, escolas, clubes e famílias. 
Mulher e família no Programa Bolsa-Escola

discuto e problematizo, neste artigo ${ }^{3}$, alguns dos mecanismos e estratégias acionadas pelos processos sociais, culturais e políticos que se articulam em torno de significados construídos para a maternidade na contemporaneidade.

A maternidade será teorizada como uma marca de gênero, produzida por um grupo específico em um determinado tempo histórico, $e$ as instituições sociais, que incluem a escola $e$ a família, serão percebidas como locus que produzem e/ou veiculam marcas como essa. Tais marcas atravessam as práticas maternas $e$ docentes, mas também muitas outras atividades em que as mulheres exercem o cuidado e a educação das crianças.

Colocar a maternidade sob o caráter da provisoriedade e da contingência pode significar a alteração de algumas crenças do projeto de construção da sociedade moderna, dos processos que constituem desigualdades e hierarquias em relação a gênero - isto $e ́$, de modelos sociais que em diferentes momentos $e$ circunstâncias investem nas mulheres a partir de uma suposta essência universal e biológica que as posiciona como provedoras, protetoras, cuidadoras e educadoras "naturais" das crianças.

Em meio a vários materiais que divulgam $e$ atuam na produção de maternidade, escolhi para a realização das análises um conjunto de anúncios televisivos que divulgaram o Programa no seu primeiro ano de implantação. Isso por considerar que o Programa agrega um amplo e importante conjunto de ações que, juntamente com outros programas elaborados e executados pelo Governo para um segmento amplo da população, buscam investir numa política de distribuição de renda aliando objetivos como a

3 Este artigo, apresentado no I Simpósio Brasileiro de Gênero \& Mídia PR/2005, é um desdobramento de minha dissertação de mestrado em Educação - "... Um cartão [que] mudou nossa vida"? Maternidades veiculadas e instituídas pelo Programa Nacional Bolsa-Escola (Klein, 2003) -, desenvolvida sob orientação da prof ${ }^{a} d^{a}$. Dagmar Meyer na Linha de Pesquisa Educação e Relações de Gênero. Dois outros artigos também são desdobramentos dessa dissertação - "A produção da maternidade no Programa Bolsa-Escola" (Klein, 2005) e "A Educação de mulheres como mães e professoras no Programa Nacional Bolsa-Escola" (Klein, 2006). 
erradicação do trabalho infantil e o acesso à educação, ao mesmo tempo em que constroem sentidos e significados para a maternidade.

As proposições veiculadas pelo Programa tratam de vincular as mulheres ao exercício da maternidade através do cumprimento de um conjunto de práticas, tais como ser fiscal da educação das crianças e administrar a renda familiar, entre outras. A partir dessa vinculação, o Programa pretende contribuir para a resolução de problemas sociais, como a redução da corrupção, da violência, da migração, da evasão e da repetência, bem como favorecer o crescimento econômico, a melhoria da saúde, a auto-estima das famílias e a valorização da mulher.

Uma das maneiras de realizar essa discussão pode ser por meio da análise das formas que pretendem fixar e ensinar acerca do ser mulher e mãe em nossa sociedade, tal como isso se dá no próprio Programa Bolsa-Escola ou em sua relação com discursos que são produzidos e que circulam em outras instâncias sociais. Ao ser colocada em discurso, a maternidade adquire diferentes significados sociais, culturais e políticos que atuam e produzem efeitos sobre o corpo, atitudes e comportamentos, enfim, sobre os modos como nos tornamos homens e mulheres, pais e mães em nossa sociedade.

\section{Gênero e educação: a quem o Programa Bolsa-Escola se dirige?}

$\mathrm{Na}$ perspectiva dos Estudos Culturais e dos Estudos Feministas que se aliam às análises de autores/as pósestruturalistas, o vínculo entre os conceitos de identidades de gênero, discurso e poder passa a ser central.

A centralidade da linguagem como constitutiva do social $e$ da cultura pode ser explorada pela adoção do conceito de discurso proposto por Michel Foucault. Para esse autor, o discurso atua enquanto um conjunto de saberes e práticas "(...) que formam sistematicamente os objetos de que falam" (Foucault, 2000:56). Meyer escreve: 
Mulher e família no Programa Bolsa-Escola

O discurso que estaria supostamente descrevendo esse real está, de fato, implicado na construção desse real e de seus sujeitos. Os discursos constroem e implementam significados na sociedade por meio de diferenciações que dividem, separam, incluem e excluem e que, por se constituírem em dinâmicas de poder, produzem e legitimam o que, aí, é aceito como verdade (Meyer, 2000b:55).

Em articulação com a noção de discurso, Meyer aponta para o emprego de possibilidades analíticas que permitem aos seres humanos compreenderem a si mesmos dentro de uma cultura específica. Embora essa abordagem enfatize a dimensão da produção discursiva do social e dos sujeitos, ela não nega a existência material das pessoas, coisas e eventos, mas

[...] sustenta que elas não têm, em si, significados fixos, uma vez que elas significam e se tornam verdadeiras somente dentro, ou pela articulação, de determinados discursos enraizados em contextos particulares e localizados (Id. ib.:57).

Assim, é através dos discursos que se produz o "real", incluindo-se aí os sujeitos que nele estão envolvidos. O real é fruto de relações de poder e também gera efeitos de poder. Deve-se examinar como o discurso funciona $e$ que significados $e$ pertencimentos sociais ele coloca em funcionamento, bem como indagar: Quem está autorizado a falar? Que pontos de vista preponderam sobre outros? Que instituições incitam e tornam legítimas algumas "verdades" acerca de gênero?

A atenção às linguagens $e$ às formas que constituem as diferenças $e$ as categorizações entre masculino e feminino passa a ser uma tentativa de apreender como o gênero é utilizado para organizar, a partir de um conjunto de significados e símbolos construídos, as relações sociais em meio a relações de poder. $\mathrm{O}$ poder, segundo Foucault (1993), é um elemento produtivo, cuja 
positividade atua e se estabelece em rede. O poder só pode funcionar mediante a formação de saberes.

Tais relações de poder não funcionariam se os seus efeitos, envolvendo aqui os significados produzidos na cultura, não contribuíssem para produzir e fixar diferentes posições de sujeito. À medida que somos representados ou interpelados através das práticas culturais é que ocorre, na cultura, a luta para produzir e definir identidades sociais. Geralmente, essas identidades são apresentadas como se fossem absolutas, coerentes $e$ universais, isto é, como uma referência verdadeira a partir da qual estabelecemos critérios de categorização para dizer quem pertence ou não pertence a uma determinada identidade ou grupo cultural. Na perspectiva teórica que adoto, no entanto, a identidade não é "natural", tampouco fixa - ela é fundamentalmente histórica, contingente e objeto de incessante re/construção. As identidades só definem-se por meio de um processo de produção da diferença, um processo que é, acima de tudo, cultural e social. Diferença e identidade, segundo Silva (2000), não são, portanto, produtos da natureza, mas produzidas no interior de práticas de significação, e os seus significados são negociados, contestados, modificados.

A identidade e a diferença resultam de processos lingüísticos organizados, fundamentalmente, a partir de critérios de valoração $e$ de hierarquia. Tais construções ocorrem de acordo com posições $e$ interesses dos diferentes grupos sociais que ocupam lugares distintos na escala social e que estão, portanto, envolvidos nas relações de poder. As categorizações efetivam-se marcando o que é "superior" ou "inferior" em relação ao que se produz como sendo o outro, podendo-se considerar a identidade inferior como aquela que é marcada e apresentada pela negação; por exemplo, inferior a uma suposta identidade mestra que, por sua vez, é apresentada como sendo a natural ou a mais verdadeira. Muitos anúncios, propagandas, reportagens e matérias jornalísticas, conhecimentos escolares e políticas governamentais estão envolvidos nesse processo de valoração e categorização, tanto 
Mulher e família no Programa Bolsa-Escola

para marcar interesses e pertencimentos de grupos considerados hegemônicos quanto para marcar e produzir o que se lhes opõe.

Ao levar em conta as identidades de gênero como construções discursivas, as análises de teóricas feministas ligadas ao pós-estruturalismo têm discutido e privilegiado as dimensões que levam em conta o caráter provisório dos termos mulher/homem e feminilidade/masculinidade, chamando a atenção para o fato de que esses domínios estão relacionados à heterogeneidade e à historicidade presentes no campo da cultura. Essa compreensão aponta para o caráter conflitivo e contingente que está envolvido na formação do gênero.

Nessa perspectiva, o corpo torna-se um local privilegiado de inscrição da diferença e da identidade e é através dos processos culturais que ele passa a ganhar sentido. Rejeitam-se aqui as explicações que tratam do corpo como uma entidade biológica $e$ universal para entendê-lo e teorizá-lo como um construto sociocultural e lingüístico que se define no interior de redes de poder (Meyer, 2003a).

Há uma multiplicidade de espaços e meios envolvidos tanto na produção das identidades sociais quanto na produção de algumas "verdades" em que acreditamos sobre o mundo $e$ a nossa forma de viver. Os/as teóricos/as que têm discutido e problematizado como essas instâncias (que podem ser escolas, igrejas, clubes, academias, cinemas, shoppings, jornais, revistas, vídeo games, TV, brinquedos, etc.) estão envolvidas nos processos de educação e cultura denominam-nas de pedagogias culturais.

Através dessas pedagogias são veiculados múltiplos discursos que pretendem ensinar, por exemplo, o que é correto ou impróprio para os corpos, nomeando-os, descrevendo-os e conformando neles determinadas atitudes, comportamentos, condutas, prazeres, gestos, só para citar alguns exemplos. Assim, diferentes discursos disputam o poder de produzir e fixar no corpo quem é educado, sadio, adequado, perfeito, em forma, de boa aparência, ao mesmo tempo em que atuam na produção de diferenças e hierarquias envolvidas com a formação das 
identidades de gênero que assumimos e em que passamos a nos reconhecer. No que concerne a gênero, cabe dizer que não se trata de negar a materialidade dos corpos e das coisas, mas de rejeitar a existência de algum sentido inato, preexistente ou universal que, muitas vezes, é utilizado para explicar e/ou justificar determinadas diferenças e hierarquias sociais.

Porém, algumas características e atributos são usualmente inscritos no corpo de mulheres e homens a partir de premissas que se articulam com a noção de existência de uma suposta essência masculina ou feminina. Sentimentos e comportamentos sociais apresentados por alguns grupos como os mais verdadeiros tornam-se imperativos em programas educacionais e propostas de saúde pública, em manuais e guias de comportamento e saúde, bem como em propostas e conteúdos curriculares. Algumas formas de viver $e$ de sentir a feminilidade/masculinidade $e$ a maternidade/paternidade são colocadas como universais $e$ inerentes aos indivíduos. Segundo Meyer (2003a), é a partir de uma "autoridade científica", presente em campos de conhecimentos como Educação e Saúde, que se atualizam e se repetem continuamente os modos como mulheres $e$ homens devem ser, assim constituindo-se importantes estratégias de naturalização e universalização de noções e conceitos.

É exatamente na perspectiva de "desnaturalizar" e politizar essa "ciência natural" que algumas teóricas feministas, por exemplo, têm rejeitado historicamente a simplificação de mulher igual a mãe. Para contestar tentativas de naturalização que estariam sendo produzidas na cultura, o feminismo lançou mão de algumas propostas para abordar a questão da maternidade; entre elas, destaco como principal a recusa em identificar o feminino com o materno, pressupondo-se que a existência da mulher pode excluir a função de mãe (Tubert, 1996).

Argumentos em torno da des/naturalização de uma maternidade hegemônica como inerente às mulheres apontam para o embate que ocorre ao se assumir o conceito de gênero como ferramenta analítica. Para os/as estudiosos/as dessa vertente 
Mulher e família no Programa Bolsa-Escola

teórica, gênero passa a complexificar, simultaneamente, as noções de corpo, sexo e sexualidade. Nesse sentido, utilizar o conceito como ferramenta analítica implica tanto apreender o caráter político do seu uso como introduzir importantes mudanças epistemológicas no campo dos Estudos Feministas. O conceito de gênero passa a indicar justamente o caráter de construção do masculino e do feminino em meio a relações de poder. Esse processo é marcado por aspectos de fluidez, pluralidade $e$ inconstância presentes na atividade de significação.

No campo dos Estudos Feministas, Linda Nicholson (2000) faz uma importante $e$ instigante discussão acerca do gênero, reportando a utilização do conceito em toda construção social relacionada ao masculino/feminino, incluindo as construções $e$ atribuições que distinguem os corpos. Segundo ela, mais recentemente, com a introdução dessa compreensão, diversos aspectos da vida social, tanto em relação ao corpo $e$ à sexualidade, quanto à masculinidade e à feminilidade, passam a ser entendidos como construtos culturais. Isto é, os estudos de gênero passam a examinar mecanismos e pressupostos de gênero que atuam no interior das diversas instituições sociais na construção do feminino e do masculino, acentuando os processos de formação das identidades, bem como seu aspecto relacional, indicando que o estudo de uma categoria pressupõe necessariamente o estudo da outra. Dessa forma, o corpo e seus processos passam a ser um importante objeto de investigação e de análise; entendendo-o como uma "variável", carrega significações bastante distintas que dependerão do lugar e do momento histórico.

Joan Scott (1995), ao teorizar sobre a produtividade do gênero como categoria analítica, indica a necessidade de se pensar gênero na articulação com outros marcadores sociais, como sexualidade, raça/etnia, classe social, geração, nacionalidade, religião, entre outros compreendidos e organizados a partir de diferenciais de poder. Através desse pressuposto, enfatiza a pluralidade e a conflitualidade presentes na cultura, a 
qual constrói e diferencia corpos masculinos e femininos. As articulações possíveis entre os indivíduos que vivem em meio a esses diferentes marcadores sociais repercutem no caráter, também plural e conflitivo, dos grupos e dos sujeitos, ao vivenciarem suas masculinidades $e$ feminilidades em diferentes momentos da vida.

Apoiada nessas autoras, Dagmar Meyer (2003b) discute como o gênero passa a funcionar como um elemento constitutivo das relações sociais e estabelece algumas produtividades do seu uso para o campo da educação. A autora acrescenta que o uso do conceito de gênero privilegia o exame dos processos de construção $e$ de naturalização das distinções de homens $e$ mulheres, mães e pais, o que nos afasta das abordagens que se restringem às discussões apenas de papéis e funções. Para Meyer (2003b), as implicações das análises de gênero levam-nos a considerar aspectos muito mais abrangentes, uma vez que tomam as instituições, os símbolos, as normas, os conhecimentos, as leis e as políticas de uma sociedade como generificadas, isto é, vêemnas como constituídas $e$ atravessadas por pressupostos $e$ representações do masculino e do feminino.

Meyer (2003b) destaca que o uso do conceito pode repercutir na elaboração e na implementação de processos que desestabilizem algumas formas de organização social (desiguais e hierárquicas) vigentes. Além disso, pode investir em projetos educativos cujo enfoque visibilize a provisoriedade e o caráter contingente do conhecimento, bem como a desnaturalização das coisas que aprendemos a tomar como dadas.

$\mathrm{O}$ leque que se abre em relação às dinâmicas de gênero instituídas e veiculadas por meio do Programa parece convergir, ou buscar intervir, através do trabalho social das mulheres, numa dada "realidade", apresentada pelos dados e pesquisas referentes à complexa situação da pobreza e da exclusão social brasileira. Talvez as mulheres ocupem uma posição central nas proposições dos programas sociais, porque elementos como nutrição, educação, saúde e necessidade de participação política e de 
Mulher e família no Programa Bolsa-Escola

ampliação das condições de trabalho, emblematicamente discutidos no âmbito do Bolsa-Escola (no contexto brasileiro, vinculados, sobretudo, ao universo feminino), encontram-se referenciados dentre os principais indicadores para medir a expectativa e a qualidade de vida da população de países como o Brasil pelo Índice de Desenvolvimento Humano (Cf. Prá, 2001).

Além disso, o Programa parece sustentar suas ações por meio de discursos que poderiam ser considerados inovadores $e$ progressistas - inclusive de algumas vertentes feministas -, na medida em que estaria investindo na valorização do "trabalho doméstico", historicamente desvalorizado na esfera social. Constatamos isso quando Cristovam Buarque, então governador do Distrito Federal, faz referência ao Programa como um "emprego social", pois "a Bolsa-Escola pode ser vista como um emprego nobre, porque assegura à mãe o salário mínimo ${ }^{4}$ para cuidar da educação de seu filho" (Buarque, 2000a:28). Os Programas da "nova geração de Proteção Social", conforme a excoordenadora do Projeto Alvorada na gestão FHC, Wanda Engel (2002), parecem convergir para isso. Ela aponta, referindo-se ao Programa Bolsa-Alimentação, as condições que as mães necessitam cumprir:

Os programas [...] agregam o direito a um apoio financeiro à responsabilidade do beneficiário no cumprimento de condicionalidades. Assim, se a mãe recebe o bolsaalimentação, por exemplo, ela terá de amamentar seu filho, registrá-lo, vaciná-lo e acompanhar seu processo de conhecimento (Engel, 2002:56, destaques meus).

4 Em 1995, em Brasília, o Programa pagava às mães um salário mínimo. 
Através das "novas"5 definições de família, também veiculadas pelo Bolsa-Escola e em grande parte dos programas sociais difundidos através da "rede de proteção social", que se torna produtivo pensar no deslizamento e/ou na redução da noção de família para a noção de mãe. Isso, porque essa operação viabiliza pelo menos dois movimentos concomitantes: um que desnaturaliza a família natural hegemônica e outro que atualiza a natureza materna da mulher.

Claudia Fonseca (2000) faz uma discussão instigante quando problematiza como tem sido empregada, por grande parte dos/as pesquisadores/as, a expressão "família chefiada por mulheres" para designar as unidades domésticas de mulheres sem marido ou nas quais a mulher é considerada o centro das decisões. A autora discute a preponderância nos estudos sobre famílias de baixa renda de uma imagem estática da unidade familiar devido a procedimentos de pesquisa que obscurecem aspectos de flexibilidade e mutação nas relações familiares presentes na organização do grupo doméstico.

A discussão de Fonseca torna-se importante para estabelecer relações com os anúncios do Bolsa-Escola, que parecem incorporar e re/produzir o pressuposto da ausência paterna, seja pela necessidade econômica que faz o pai migrar em

${ }^{5} \mathrm{Na}$ Cartilha 100 perguntas e respostas sobre a Bolsa-Escola, o então governador do Distrito Federal, Cristovam Buarque, diz: "A Bolsa Escola é um benefício pago à família, de preferência à mãe [...] ou a outra figura feminina que tenha poder de decisão e controle sobre as crianças a serem beneficiadas." (Buarque, 2000a:14). Desse modo, o Programa ao reconhecer que as mães, em muitos casos, ocupem, sozinhas, a posição de mantenedoras das famílias, admite a existência de famílias sem a presença de um par conjugal. A respeito da discussão de família no PGRFM (Programa de Garantia de Renda Familiar Mínima) de Campinas, a pesquisa de campo realizada por Ana Maria Medeiros da Fonseca, conclui "[...] que não existe à família, as entrevistadas, expressão da família perante o PGRFM de Campinas, desenham famílias. As famílias, ou grupos de parentesco reconhecidos como a família de cada uma das entrevistadas, operam com um código de lealdades e de obrigações completamente alheias à lógica colocada pelo PGRFM" (Fonseca, 2001:221). 
Mulher e família no Programa Bolsa-Escola

busca de melhores condições de vida, seja em decorrência de fatores culturais que envolvem a transitoriedade das relações de conjugalidade. Porém, para esta análise, a questão central é: como que, com essa "nova" conceitualização de família, discutida e incorporada pela maioria dos programas sociais, a família brasileira pobre passa a ser "naturalizada", fundamentalmente, como sendo chefiada por mulheres, matrilinear, na qual os homens parecem não existir. Ao mesmo tempo, parece não ocorrer, no âmbito desses programas, movimentos que invistam na modificação dessa situação. Referente a isso, Meyer argumenta que a mídia, "(...) ao veicular e produzir formas de pensar, dizer $e$ viver masculinidades e feminilidades, também nos educa como sujeitos de gênero" (Meyer, 2003a:8). Talvez seja justamente nessa perspectiva que possamos pensar em realizar um estranhamento nessa relação familiar e "natural" instituída pelos anúncios publicitários.

A partir dessa perspectiva, podem-se tomar as estratégias discursivas de "valorização da mulher", utilizadas no âmbito do Programa, para ampliar e/ou resgatar sua "auto-estima". Esses movimentos buscam tanto tomar/tornar mulher=mãe, quanto família=mãe, o que se efetiva, por exemplo, pelo pagamento do benefício e da re/colocação da mulher no centro das políticas públicas, fazendo com que funcione o cumprimento/posicionamento de alguns indivíduos em algumas funções e lugares específicos, dentre outras questões.

Mesmo que não se façam "exigências" explícitas sobre como a família=mãe deve administrar o dinheiro, há inúmeras sugestões acerca de possibilidades para fazê-lo, como podemos visualizar, por exemplo, na série de anúncios do Bolsa-Escola para a televisão, veiculados em 2001.

A intenção principal dessa primeira série de anúncios protagonizados pela atriz Paloma Duarte foi fazer com que a sociedade brasileira, sobretudo as famílias com renda per capita inferior a $\mathrm{R} \$ 90,00$ - através das mulheres-mães - se tornasse forte aliada do Governo Federal, no sentido de pressionar seus/suas 
prefeitos/as a aderirem ao Programa. De acordo com a assessora de imprensa e membro da equipe do Programa Bolsa-Escola no Governo Fernando Henrique Cardoso, esses anúncios tornaramse uma espécie de "cara" do Programa, provocando uma grande receptividade entre as famílias pobres que assistiam à atriz Paloma Duarte nos comerciais do Bolsa-Escola e na novela Porto dos Milagres, exibida em horário nobre pela Rede Globo de TV. ${ }^{6}$

Esses anúncios estão calcados em representações familiares nas quais as mulheres-mães são conduzidas/ensinadas a administrar os recursos do Programa, pois neles a atriz vai com as mães à feira, à papelaria $e$ ao comércio para comprar alimentos, material escolar e roupas. Se, na novela, a "professorinha" representava os interesses e as questões sociais de uma comunidade pobre e explorada, nos comerciais, adquiria legitimidade para olhar de frente o telespectador e persuadir as mães a tornarem-se beneficiárias do Bolsa-Escola. Autorizada a divulgar a mensagem de um programa de cunho social, seu "papel" principal era o de "aconselhar" as mães a "não deixarem os/as seus/suas filhos/as faltarem às aulas", indicando, ainda, as "melhores" formas de gastar o benefício pago mensalmente pelo Governo.

Vejamos como isso se dá em um dos anúncios do BolsaEscola, intitulado "Feira":

No vídeo, a primeira tomada é a de uma mulher miscigenada, que serve, de pé, o café da manhã aos seus/suas filhos/as - uma menina e um menino que estão uniformizados. Todos estão em um ambiente cuja mobília (de cozinha) é bastante simples.

Em um ângulo mais à frente, ficando a família ao fundo, aparece a atriz Paloma Duarte, que se dirige diretamente ao telespectador. Ela está com uma blusa branca e demonstra uma expressão tranqüila e segura.

${ }^{6}$ Essas informações foram acessadas através de conversa por telefone - (61) 410.62 .79 - no dia 27/12/2002. 
Mulher e família no Programa Bolsa-Escola

A próxima tomada mostra a menina tomando o café; ela
olha e sorri para o telespectador.
Em outra cena, a atriz aparece junto à mãe. Elas saem,
fecham o portão em frente à casa, caminham pela rua e
dirigem-se à feira. As duas colocam vários alimentos em
uma sacola e retornam para casa.
Colocam os alimentos sobre a mesa. A atriz toca em
vários deles como se estivesse demonstrando ao
telespectador o grande volume de compras realizadas
pelas duas. A próxima cena mostra novamente a atriz ao
lado da mãe. Ambas sorriem, demonstrando satisfação.
No final do anúncio, aparece a mãe, o filho e a filha na
janela de sua casa; todos sorriem e olham para o
telespectador. Então, a mãe é focada sozinha, segurando
na mão o seu cartão Bolsa-Escola.
Por fim, lado a lado, aparecem a logomarca do Bolsa-
Escola do Ministério da Educação e a do Governo
Federal.

Nesse anúncio, o texto falado pela atriz diz o seguinte:

\begin{tabular}{l}
\hline A Jacilena é mãe do Jéferson e da Flávia. O Bolsa- \\
Escola Federal do Ministério da Educação dá para cada \\
um deles 15 reais por mês para eles continuarem na \\
escola. Olha o que a Jacilena compra na feira com esse \\
dinheiro: frango, banana, tomate, milho, laranja, ovos, \\
feijão. Nossa Senhora!! Quanta coisa, Jacilena. Bolsa- \\
Escola Federal: o seu filho ganha educação, e você, uma \\
ajuda em dinheiro. \\
[Ao final, uma voz masculina diz] \\
Ministério da Educação - Boa escola para todos - \\
Governo Federal
\end{tabular}

O texto e a imagem, narrados a partir do anúncio "Feira", indicam a construção de um caminho importante para compreendermos como ocorre a associação entre a "boa" maternidade e a obtenção do sucesso familiar e social proposto 
pelo Governo. É precisamente quando as crianças aparecem uniformizadas, tomando o café da manhã e seguindo para a escola de posse de seus materiais escolares que a publicidade re/afirma, veicula e fortalece uma representação de família=mãe que necessita priorizar (e administrar) a compra do uniforme, do material escolar e de alimentos para as crianças.

Diante do recebimento do benefício, Jacilena pode/deve ir à feira comprar os alimentos para sua família, estabelecendo-se e re/incorporando-se alguns percursos "naturais" das mulheres. No caso dos anúncios, essa incorporação refere-se a maneiras de pensar e consumir que priorizam o cuidado e a educação dos/as filhos/as. Também quando as crianças aparecem sorridentes $e$ felizes no vídeo, pode-se apreender como as famílias, através das mulheres-mães, ao aderirem às orientações propostas pelo Programa, promovem a inclusão das crianças na escola e na vida. As mães seguram e mostram ao telespectador com satisfação o cartão Bolsa-Escola, que, nesse contexto, se torna generificado, pois passa a significar "ascensão" social e garantia de uma vida melhor às mulheres-mães pobres.

Por meio desse anúncio, podemos pensar, ainda, na relação intrínseca que se estabelece entre educação, gênero e classe, pois as mulheres-mães que vivem abaixo da linha da pobreza são levadas a reconhecer-se a partir de uma dimensão social e econômica generificada, que as posiciona, sobretudo, como as únicas e/ou principais gerenciadoras da família e dos recursos pagos pelo Programa. A forma como as mulheres-mães são representadas nos anúncios posiciona as mulheres, mais uma vez, ao lado do Estado, como co-responsáveis pela inclusão e pelo sucesso escolar das crianças. Essa relação alude aos possíveis sentidos que se estabelecem para o Estado ao prover o benefício para a mulher administrar, uma vez que, nos diversos materiais veiculados através do Programa, o pai biológico é deslocado, de tal forma que parece estar sendo substituído pelo Estado, o qual se torna, nessa relação, equivalente ao pai. 
Mulher e família no Programa Bolsa-Escola

No anúncio "Feira", assim como nos demais, são utilizadas estratégias e linguagens variadas (sons, imagens, cores, lugares e expressões) que tratam de atribuir e naturalizar funções e lugares sociais específicos das mulheres - gerenciar a família e os recursos financeiros -, enquanto o Governo assume o lugar de "provedor da família", garantindo a educação e a "ajuda em dinheiro", função que, em geral, foi atribuída e desempenhada historicamente pelos homens-pais. No que tange à classe $e$ ao gênero, a propaganda indica nitidamente quem pertence ao grupo social dos/as beneficiados/as pelo Programa e o que cada indivíduo pode/deve fazer.

Portanto, o processo educativo que envolve as mães dá-se na relação entre a utilização "correta" do dinheiro pago pelo Programa e os benefícios que a incorporação desses ensinamentos poderá trazer para a vida das crianças. Isso se repete em outro comercial da série, chamado "Comércio":

\footnotetext{
No vídeo, uma mulher sai da porta de sua casa acompanhada de um menino e uma menina que estão indo para a escola. As crianças estão uniformizadas e com mochilas nos ombros.

As crianças passam pelo portão e sorriem para a atriz Paloma Duarte, que está de pé, à esquerda do vídeo, próxima dessa passagem. A atriz retribui o sorriso à menina e dirige-se ao telespectador, sorrindo $e$ demonstrando satisfação.

Em seguida, a atriz e a mãe estão em um atacado de roupas. Elas escolhem alguns artigos.

$\mathrm{Na}$ última cena, aparecem as crianças sentadas na escada da casa junto com sua mãe, que segura orgulhosa o cartão Bolsa-Escola. Há, ainda, uma tomada da menina, que olha e sorri para o telespectador. Após, é a vez da mãe, que também olha e sorri para o telespectador. Por fim, lado a lado, aparecem a logomarca do Bolsa-
} 


Escola do Ministério da Educação e a do Governo
Federal.

O texto falado é o seguinte:

A Adriana é mãe do Silvani, da Aline e do Diego. O BolsaEscola Federal do Ministério da Educação dá para cada um deles 15 reais para eles continuarem na escola. Olha o que a Adriana compra de roupa com esse dinheiro!!! Chinelo, tamanquinho prá Aline, shortinho, saia, camisetas, calça, bermudão.

- Tá tudo aí?

- Tá tudo em ordem.

- A criançada vai gostar!!

- Vai adorar!!

- Hei tá!!

Bolsa-Escola Federal, o seu filho ganha educação, e você, uma ajuda em dinheiro.

[Ao final, uma voz masculina diz]

Ministério da Educação - Boa escola para todos -

Governo Federal.

A partir desses ensinamentos, dirigidos exclusivamente às mulheres-mães, podemos pensar: Quais pressupostos de gênero, atrelados à classe, estão embutidos nesses comerciais? Como esses pressupostos atuam para atravessar e constituir de um determinado modo os indivíduos que devem se reconhecer como alvo das políticas de inclusão social na sociedade brasileira 
Mulher e família no Programa Bolsa-Escola

contemporânea? Por que os homens-pais não se constituem como alvo dos ensinamentos divulgados pelo Programa? Quais mecanismos e estratégias são utilizados para dirigir às mulheres esse conjunto de ensinamentos domésticos e de inserção social?

A discussão das representações de gênero na publicidade e, em especial, nos anúncios do Bolsa-Escola pode indicar alguns significados socialmente construídos acerca dos corpos dos indivíduos, seus costumes, crenças e formas de viver. As representações de gênero veiculadas na mídia precisam ser pensadas como parte integrante de uma sociedade que imprime determinadas marcas que deverão estar em consonância com dimensões políticas, econômicas e culturais hegemônicas.

Localizar e descrever essas noções pode significar visibilizar algumas tentativas e estratégias nas quais alguns grupos buscam marcar/produzir um conjunto de significações (comportamentos, valores, atitudes, gestos, etc.) sobre outros. Isto é, pode-se mostrar como atuam forças e poderes que disputam a imposição de significados para o social.

Rosa Fischer defende a tese de que a televisão, enquanto um meio de comunicação social ou como uma linguagem audiovisual particular,

(...) tem uma participação decisiva na formação das pessoas - mais enfaticamente, na própria constituição do sujeito contemporâneo. (...) Pode-se dizer que a TV, ou seja, todo esse complexo aparato cultural e econômico - de produção, veiculação e consumo de imagens e sons, informação, publicidade e divertimento, com uma linguagem própria - é parte integrante e fundamental de processos de produção de significados e sentidos, os quais por sua vez estão relacionados a modos de ser, pensar, a modos de conhecer o mundo, de se relacionar com a vida (Fischer, 2001b:15).

A mídia, que também inclui a publicidade, através das suas imagens, sons, cores, expressões, luzes e tomadas, exerce sobre 
nós uma espécie de pedagogia capaz de orientar/ensinar modos específicos de pensar, agir, consumir e relacionar-se com o mundo. Dessa forma, ela veicula $e$ institui conhecimentos de acordo com critérios que se conjugam a processos de valoração, hierarquização e seleção, tornando-se um mecanismo hábil para conduzir, organizar e regular o funcionamento dos espaços, instituições e/ou a conduta dos indivíduos, como evidencia a fala da atriz no anúncio "Comércio":

olha o que a Adriana [ou a Jacilena] compra[m] com esse dinheiro!! Chinelo, tamanquinho prá Aline, shortinho, saia, camisetas, calça, bermudão [e exclama] A criançada vai adorar... [ensinando e conduzindo a mãe a cumprir a proposição do Governo, explicitada na frase final] BolsaEscola Federal, o seu filho ganha educação, e você, uma ajuda em dinheiro.

Quando a atriz diz que a criançada "ganha educação" porque a mãe "ganha a ajuda em dinheiro", atrela-se, mais uma vez, o recebimento dessa "ajuda" ao cumprimento e à realização de algumas funções imbricadas em representações de gênero ainda vigentes em nossa sociedade, que, de alguma forma, precisam ser re/investidas. As relações entre as pessoas, nesses comerciais, parecem marcadas por um processo de diferenciação "natural", no qual todos ocupam os seus lugares: a atriz, anunciando o Programa; as mães, ouvindo, cumprindo $e$ recebendo funções; $e$ o Governo, criando, justificando $e$ mantendo o Programa, representado, no final, pela apresentação das logomarcas e da voz masculina que diz: "Ministério da Educação - Boa escola para todos - Governo Federal".

Problematizar a forma como são construídos e disputados os significados e representações maternas (e familiares) apresentadas nos anúncios pode também levar à problematização do caráter produtivo da cultura. Com isso, podem-se compreender algumas implicações que essa produção mantém e re/inventa para a sociedade, fundamentalmente quando convergem com as 
Mulher e família no Programa Bolsa-Escola

discussões e os interesses sociais, econômicos e políticos, que, no contexto desta pesquisa, são extremamente relevantes.

\section{Algumas conclusões}

As ações desenvolvidas pelo Programa traçam caminhos que tentam consolidar os objetivos divulgados pelo Ministério de Educação e Cultura através da Secretaria do Programa Nacional de Bolsa-Escola. É interessante analisar as formas de divulgação dessas propostas e ensinamentos à população brasileira por meio de propagandas, guias, manuais ou cartilhas, tal como a intitulada Educar é uma tarefa de todos nós (Abreu, 2002). Ou seja, trata-se de divulgações que incorporam uma série de "procedimentos" didáticos que visam esclarecer, informar e estabelecer as ações que deverão ser cumpridas passo a passo, construindo de forma contínua e gradual uma espécie de currículo que engloba um extenso conjunto de orientações nas quais as mulheres-mães são posicionadas como "sujeitos aprendentes" privilegiados.

Os discursos constitutivos dessa maternidade expressam-se na fala de médicos/as, psicólogos/as, assistentes sociais $e$ especialistas de educação. Especialmente no que se refere ao Programa, esses discursos repercutem, como já indiquei, na fala da atriz Paloma Duarte, que protagoniza os comerciais de TV em horário nobre, na fala de ministros, assessores/as, prefeitos/as, diretores/as de escola, funcionários/as das secretarias de educação e de muitos outros órgãos envolvidos. A cada um/a que fala sobre a maternidade é conferido um lugar de autoridade que se relaciona hierarquicamente com a fala de outros sujeitos. É por meio desses lugares de enunciação que se multiplica a prática das mulheres-mães - nas inúmeras representações divulgadas nas propagandas de canal aberto de TV, nos artigos assinados pelo Ministro e publicados em jornais diversos e em inúmeras reportagens que aparecem nos jornais e revistas em nível nacional. São materiais que "(...) constituem uma base material 
sobre a qual e a partir da qual se dispersam inúmeras [maternidades]" (Fischer, 2001a:209).

A exemplo disso, ao argumentar com os prefeitos sobre a criação dos programas sociais, demonstra a importância do envolvimento das mães para a sociedade, pois são elas que "(...) deverão comprovar o comparecimento de seus filhos em programas de vacinação e outros serviços públicos de prevenção da saúde infantil e materna" (Buarque, 2000b:). O trabalho das mães produzirá uma série de efeitos sociais determinantes para “(...) quando essas crianças chegarem à escola. Elas [com a ajuda das mães] estarão preparadas para desenvolver plenamente a sua capacidade intelectual e para acompanhar a educação formal" (Id. ib.: 2000b).

Destacam-se representações de mães que precisam se envolver nas tarefas escolares das crianças, ensinar com paciência e amor, comprovar o comparecimento das crianças em programas de vacinação e saúde infantil, participar de programas de alfabetização ${ }^{7}$ e capacitação profissional, administrar "bem" o benefício pago em dinheiro pelo Programa, enfim, cumprir responsabilidades que as legitimam como "cuidadoras" $e$, sob alguns aspectos, também "provedoras" do núcleo familiar. Por isso, elas são definidas nos anúncios televisivos e nos demais materiais de divulgação do Programa como mais capazes de exercer o controle da educação de seus/suas filhos/as.

As representações veiculadas no Programa acionam noções que nos permitem e/ou remetem a pensar no cuidado, no cumprimento de tarefas domésticas, no compromisso com a participação escolar como valores inerentes e/ou naturais à maternidade, por meio de representações de mães afetivas,

7 De acordo com a reportagem "Mães serão prioridade no programa de alfabetização do governo", o Ministério da Educação buscou priorizar a alfabetização das mães, sobretudo das que fazem parte do Programa BolsaEscola. Para o ex-ministro, Cristovam Buarque, a alfabetização das mães estimula a permanência de seus/suas filhos/as no colégio além de melhorar no auxílio dos trabalhos escolares (Mães..., 2003). 
Mulher e família no Programa Bolsa-Escola

protetoras e participativas; mães que administram, organizam, fiscalizam e gerenciam a casa e a educação das crianças; enfim, mães que educam e necessitam educar-se constantemente. Às formas de representar a maternidade, articulam-se as formas de apresentar, descrever, conhecer e delegar, a esse sujeito mãe, atributos e características tidas como as mais verdadeiras.

O Programa, ao garantir o benefício financeiro às mães e ao incentivá-las a formar centros de cuidado infantil e a acompanhar a saúde das crianças, levando-as ao posto médico, re/afirma que os cuidados infantis devem ser exercidos pelas mulheres e não pelos homens. Nesse contexto, torna-se importante perguntar sobre os possíveis efeitos que esse conjunto de ensinamentos irá produzir na vida das famílias beneficiadas pelo Programa.

Se considerarmos, como Meyer et al. (2003b), ${ }^{8}$ que educar envolve o conjunto de processos pelos quais os indivíduos são transformados ou se transformam em homens $e$ mulheres específicos no âmbito de uma cultura $e$, ainda, que os sistemas de representação englobam práticas de significação lingüística $e$ cultural e sistemas simbólicos pelos quais os significados (que permitem a mulheres $e$ homens entender suas experiências $e$ delimitar modos de ser e viver) são construídos, teremos que nos perguntar em que tipos de pais e de mães essa linguagem de programas como o Bolsa-Escola pode estar transformando os homens e mulheres dos segmentos sociais que busca atingir. Mais do que isso, tais pressupostos deveriam levar-nos a perguntar se essas representações são suficientemente inclusivas para dar conta dos desafios que a pobreza e a profunda desigualdade social que caracterizam a sociedade brasileira nos colocam $e$, ainda, a

8 O artigo "'Mulher sem-vergonha e traidor responsável': problematizando representações de gênero em anúncios televisivos oficiais de prevenção ao HIV/AIDS", desdobra-se do Relatório de Pesquisa intitulado "Educação, saúde, gênero e mídia: um estudo sobre HIV/AIDS-DSTs com Agentes Comunitários de Saúde do Programa de Saúde da Família em Porto Alegre/RS" (Meyer et alii, 2003b). 
questionar os efeitos que elas exercem sobre aqueles e aquelas que não se incluem em suas descrições.

\section{Referências bibliográficas}

ABREU, Ana Rosa et al. Educar é uma tarefa de todos nós: um guia para a família participar no dia-a-dia, da educação de nossas crianças. Dia Nacional da Família na Escola. Brasília, Ministério da Educação, 2002 [Publicação enviada às escolas brasileiras].

BUARQUE, Cristovam. 100 perguntas e respostas que você precisa saber sobre a Bolsa-Escola. $2^{\mathrm{a}}$ ed., Brasilia, 2000a.

- Onze ações para Você Cuidar das Crianças do seu Município. Brasilia, 2000b (http:// www.missaocriança.org.br).

ENGEL, Wanda. Combater a desigualdade: um desafio de todos nós. Social Democracia Brasileira, n 2, Brasilia, Instituto Teotônio Vilela, março, 2002, pp.55-57.

FISCHER, Rosa Maria Bueno. Foucault e a análise do discurso em educação. Cadernos de Pesquisa, $\mathrm{n}^{\circ}$ 114, São Paulo, Fundação Carlos Chagas, Editora Autores Associados, novembro, 2001a, pp.197-223.

Televisão e Educação: Fruir e pensar a TV. Belo Horizonte, Autêntica, 2001.

FONSECA, Ana Maria Medeiros da. Família e política de renda mínima. São Paulo, Cortez, 2001.

FONSECA, Claudia. Família, fofoca e honra: etnografia de relações de gênero e violência em grupos populares. Porto Alegre, Ed. Universidade/UFRGS, 2000.

FouCAULT, Michel. A arqueologia do saber. $6^{\mathrm{a}}$ ed. Rio de Janeiro, Forense Universitária, 2000.

. Microfísica do Poder. 11ª ed. Rio de Janeiro, Graal, 1993.

KLEIN, Carin. "...Um cartão [que] mudou nossa vida"? Maternidades veiculadas/instituídas pelo Programa Nacional de Bolsa-Escola. Dissertação de Mestrado, PPGEDU/UFRGS, 2003. 
Mulher e família no Programa Bolsa-Escola

A Educação de mulheres como mães e professoras no Programa Nacional Bolsa-Escola. Educação e Realidade, vol. 30, n ${ }^{\circ}$ 2, Porto Alegre, UFRGS, 2006, pp.221-252.

A produção da maternidade no Programa Bolsa-Escola.

Estudos Feministas, vol 13, $\mathrm{n}^{\circ}$ 1, Florianópolis, CFH/CCE/UFSC, 2005, pp.31-52.

MEYER, Dagmar. Gênero e Educação: teoria e política. In: LOURO, Guacira Lopes et alii. (orgs.) Corpo, gênero e sexualidade: um debate contemporâneo na educação. Petrópolis, Vozes, 2003a.

et alii. Mulher sem vergonha e traidor responsável: problematizando representações de gênero em anúncios televisivos oficiais de prevenção ao HIV/AIDS. Relatório de Pesquisa "Educação, saúde, gênero e mídia: um estudo sobre HIV/AIDS-DSTs com Agentes Comunitários/as de Saúde da Família em Porto Alegre, RS", Faculdade de Educação, UFRGS, Porto Alegre, mimeo., 2003b.

As mamas como constituintes da maternidade: Uma história do passado? Educação e Realidade, vol. 25, $\mathrm{n}^{\circ}$ 2, Porto Alegre, FACED/UFRGS, jul/dez, 2000a, pp.117-133.

Identidades Traduzidas. Cultura e docência teuto-brasileiroevangélica no Rio Grande do Sul. Santa Cruz/RS, EDUNISC; Sinodal, 2000b.

NICHOLSON, Linda. Interpretando o gênero. Estudos Feministas, $n^{\circ} 2$, 2000, pp.9-41.

PRÁ, Jussara Reis. Cidadania de gênero, capital social, empoderamento e políticas públicas no Brasil. In: BAQUERO, Marcello. (org.) Reinventando a sociedade na América Latina: Cultura política, gênero, exclusão e capital social. Porto Alegre/Brasília, Ed. Universidade/UFRGS/Conselho Nacional dos Direitos da Mulher (CNDM), 2001, pp.173-208.

SCOTT, Joan. Gênero: uma categoria útil de análise histórica. Educação e Realidade, vol. 20, n 2, julho/dezembro, 1995, pp. 71-99.

SILVA, Tomaz Tadeu da. (org.) Identidade e diferença: a perspectiva dos estudos culturais. Petrópolis-RJ, Vozes, 2000.

TUBERT, Silvia. Introduccion. In: TUBERT, Silvia. (ed.) Figuras de la madre. Madrid, Ediciones Cátedra, 1996, pp.7- 37. 
Carin Klein

Matéria de Jornal

Mães serão prioridade no Programa de Alfabetização do Governo. O

Estado de S.Paulo, 19 de abril de 2003, Educação (http://www. estadão.com.br). 